\title{
Sobre a justiça: as críticas de Anderson ao igualitarismo da sorte
}

\author{
THIAGO AUGUSTO PASSOS BEZERRA *
}

\begin{abstract}
RESUMO Intentamos nesse artigo apresentar as críticas da filósofa Elizabeth Anderson expostas emWhat is the point of equality? ao que ela considera comoigualitarismo da sorte, na medida em que mostraremos as principais razões que a levaram considerar essa tese como injusta. Portanto, nossa abordagem se dará em três partes; primeiro, apresentaremos sucintamente em que consiste a tese geral do igualitarismo, em dois grupos, quais sejam; os igualitaristas de recursos e os de bem-estar. Segundo, exporemos as razões que levaram Anderson a denominar essas vertentes do pensamento igualitarista como igualitarismo da sorte. Por fim, cumpriremos nosso objetivo que consiste em tratar dos argumentos que refutam a tese do igualitarismo da sorte mostrando-o injusto, bem como revelando quais argumentos levariam à adesão da tese do igualitarismo democrático como opção alternativa.
\end{abstract}

PALAVRAS-chaVe Justiça: Igualdade; Liberdade; Democracia.

PARA A TRADIçÃo das teorias do "contrato social" a questão da justiça é intrínseca ao contrato enquanto um acordo, estabelecido entre os indivíduos para fundamentar a agregação comunitária e organizar a vida social. O pressuposto desse acordo fora entendido por pensadores modernos de diversas formas, na medida em que versaram sobre a justiça em suas várias nuances e facetas de liberdade e igualdade. É importante notar que essa discussão está para além de qualquer circunscrição histórica, embora em cada período os pensadores intentassem responder às demandas próprias e tenham apresentado soluções distintas. Ao olhar em perspectiva a história da filo-

* Universidade Federal do Rio de Janeiro Mestrando no Programa de Pós-graduação Lógica e Metafísica Bolsista CAPES 
sofia, são-nos apresentados pensadores tais como Kant, que endossam a precedência da liberdade como fundamento de nossas ações políticas e jurídicas. Por outro lado, situam-se pensadores como Aristóteles insistindo que a igualdade é a base da justiça e, por conseguinte, deve ser a norteadora das políticas públicas. Configura-se então como um dos principais problemas da filosofia política a tentativa de equacionar de forma satisfatória a relação entre liberdade e igualdade.

Na contemporaneidade, certamente, é a partir das contribuições de John Rawls que os debates sobre a igualdade como importante aspecto da justiça, e imprescindível para sua concretização, foram reabilitados. Sabemos que o filósofo elabora um procedimento tendo em vista estabelecer princípios básicos de justiça que devem reger uma sociedade democrática ${ }^{1}$. Esse procedimento consiste em tomarmos uma situação hipotética, chamada de "posição original”, em que os indivíduos fariam um contrato de certos princípios para depois formular uma constituição e, assim, fundar as demais instituições necessárias para cooperação entre os indivíduos, entendidos agora enquanto cidadãos. Ocorre que, de acordo com o argumento de Rawls, esses indivíduos na posição original se encontrariam numa circunstância peculiar, qual seja; sob o "véu da ignorância”. Rawls argumenta que nessas circunstâncias seriam adotados os seguintes princípios de justiça: (i) todos teriam igual direito às liberdades básicas e (ii) diferenças na distribuição de riquezas poderiam ser admitidas caso fossem vantajosas para todos e atreladas a funções abertas a todos. Contudo, também defende uma regra de prioridade, quer dizer, eventualmente se esses dois princípios entrarem em conflito, o primeiro princípio deverá sobrepor-se ao segundo. Dito de outro modo, as liberdades terminam assumidas como mais importantes do que as possíveis desigualdades econômicas e sociais.

A influência que Uma Teoria da Justiça exerceu sobre a intelectualidade ocidental foi sentida na vasta repercussão que se seguiu, bem como nas propostas complementares ou mesmo alternativas apresentadas em trabalhos como os de Dworkin, que contrapõe o modelo construtivista e procedimental de Rawls aos modelos naturalistas de justificação ${ }^{2}$. Argumenta que a prioridade dada por Rawls ao primeiro princípio não

1 Cf. RAWLS, 1975.

2 Certamente que entre os teóricos do "contratualismo social” este não é um ponto pacífico de discussão. É claro que nem o Estado ou mesmo a moral tem sua gênese por meio de um contrato real entre indivíduos que podemos chamar auto interessados. Como destaca ARAÚJO (2009, p. 12): 
se sustenta, considerando como uma posição injustificada a tese de que qualquer ser racional, uma vez tendo as condições mínimas de vida satisfeitas, preferiria um acréscimo de liberdade e não de riqueza material ${ }^{3}$. Ademais, argumenta que mesmo na condição de estarem sob o suposto "véu da ignorância” não necessariamente os indivíduos contratariam os princípios mencionados acima. O que Dworkin quer mostrar é que o fundamento do primeiro princípio da justiça é o direito originário que cada pessoa tem de ser respeitada e considerada de modo igualitário. Quer dizer, a posição original é caracterizada de modo a ficar evidente, na linha argumentativa de Dworkin, que a igualdade é o princípio fundamental e não as diversas liberdades individuais 4 . Por isso, o direito à igualdade de tratamento é devido aos seres humanos enquanto pessoas morais. A conclusão não pode ser outra senão a de que a igualdade é a noção fundamental e a que dá legitimidade ao primeiro princípio de Rawls, de maneira que a teoria política de Dworkin deve ser entendida enquanto um Igualitarismo e não uma forma qualquer de liberalismo ${ }^{5}$.

O que Anderson indica em seu célebre artigo What is the point of equility? é que a composição de trabalhos acadêmicos que, a princípio, resgatam a questão da igualdade, assumindo-a com a mesma dignidade que fora conferida à liberdade, nutre uma forma de conservadorismo. É sabido que o Igualitarismo se compreende enquanto uma doutrina, grosso modo, que defende a igualdade de direitos e oportunidades na esfera social $^{6}$. A igualdade parece estabelecer uma relação intrínseca com a liberdade, isto porque, na medida em que não há condições iguais de aprimoramento e exercício de capacidades, é improvável que se exerça a liberdade em plenitude. Não há plenitude

"a moral provavelmente surgiu, e tradicionalmente foi justificada, por apelo a ideias religiosas e metafísicas. Contudo, as razões em função das quais uma determinada prática surgiu não precisam necessariamente ser as mesmas funções que, retrospectivamente, apresentamos para nossa participação e endosso dessa prática".

3 Cf. DWORKIN, 1975, p. 17

4 "o direito ao igual respeito não é um produto do contrato, mas a condição de admissão na posição original” (DWORKIN, 1975, p. 51)

5 Cf. DALL'AGNOL, 2005, p. 58

6 Popper afirma que o Igualitarismo na perspectiva liberal se compreende enquanto "a exigência de que todos os cidadãos do Estado sejam tratados imparcialmente. É a exigência de que o nascimento, relações familiares ou riqueza não influenciem aqueles que aplicam a lei aos cidadãos. Em outras palavras, o Igualitarismo não reconhece privilégios naturais, embora certos privilégios possam ser conferidos pelos cidadãos aqueles em quem confiam" (POPPER, 1962, p. 89) 
de liberdade caso sua realização esteja, antes, comprometida por condições e limitações sociais, alheias ao ato de determinação e deliberação dos indivíduos, em outras palavras, a liberdade exige o suprimento de um pressuposto que é a igualdade. Numa versão que poderíamos chamar de tradicional do Igualitarismo, se entende que essas condições sociais impostas por fatores diversos, desde os biológicos aos culturais, e que, por conseguinte, independem dos indivíduos, os tornariam não imputáveis pelas consequências advindas de sua condição. No entanto, residiria nessa imputabilidade, mas que fatalmente atribuída aos indivíduos em decorrência das circunstâncias nas quais as sociedades se realizam, o fardo de injustiça arrastado pelas democracias contemporâneas e que as teses igualitaristas intentariam corrigir.

Quando analisamos os argumentos de Dworkin o Igualitarismo poderia ser assumido como uma espécie de distribuição de recursos. Evidentemente, ressalta serem recursos alheios a qualquer manifestação de cobiça por parte dos indivíduos, contudo, isto pode conduzir a consequências eventualmente falaciosas ${ }^{7}$. Como aquelas que endossam suspeitas que indiquem serem as motivações que albergam as políticas igualitárias tão somente a simples cobiça. Ao tomarmos outras propostas tendo em vista a implementação de políticas igualitaristas, ainda dentro dessa perspectiva distributivista de recursos, ambas parecem reforçar a objeção de que os igualitaristas não atentam aos limites de ação estatal sobre a vida dos indivíduos.Dentro de teses igualitaristas como as de Van Parijs, por exemplo, o Estado estaria legitimado a realizar um tipo de coerção moral ou econômica de outros para fins que sejam privados ${ }^{8}$. O argumento contra os igualitaristas de recursos pode ser resumido do seguinte modo: o conflito entre liberdade e igualdade que tais posições teóricas incitariam, provém da compreensão da liberdade enquanto à atribuição de mérito e responsabilidade a atos deliberados, ou seja, não originados por coerção. Por conseguinte, os indivíduos deveriam ser passíveis de responsabilização moral não apenas numa perspectiva negativa. Numa seara que diríamos positiva da liberdade, considerando notadamente as ações privadas, os ganhos oriundos dessas ações confere plena pertença

7 Cf. DWORKIN, 2005, p. 180

8 Cf. VAN PARIJS, 1995, pp. 32-48. 
nas conquistas de recursos e bem-estar ${ }^{9}$. Ocorre que, quando teóricos igualitaristas restringem suas análises ao que chamamos de bens divisíveis e que são apropriados de maneira privada, no caso de renda e recursos, por exemplo, acentuam esse conflito. A relação que apontamos anteriormente como inerente entre liberdade e igualdade sugere conflitos difíceis de negociar, pois, no seio dessas concepções igualitaristas, ainda que busquem a correção de injustiças, terminariam por invadir o âmbito da privacidade. Desse modo, enfraquecem suas teses e baixam à guarda para as críticas daqueles situados numa posição política mais conservadora ${ }^{10}$. Como também não respondem às demandas de um campo denominado de progressista, na medida em que negligenciam amplas pautas de movimentos políticos igualitaristas na sociedade. O que Anderson aponta é que na perspectiva da distribuição de recursos, mesmo a correção de supostas injustiças, é reduzida a casos que em nada questionam as relações de poder e opressão na sociedade ${ }^{11}$. Isto porque, argumenta a filósofa, os problemas que decorrem de posições teóricas, tais como a de Dworkin ou Van Parijs, residem no fato de que ambos adotam uma noção equivocada do sentido de igualdade. Ou seja, a dificuldade que esses igualitaristas encontram e que não conseguem responder satisfatoriamente estaria nos próprios princípios que adotam. É preciso, então, retomar os princípios para podermos encadear argumentos que façam sentido a uma concepção, de fato, Igualitarista. Quer dizer, uma doutrina em que a igualdade é aliada à

9 Nozick argumenta que a liberdade é um valor fundamental e que se sobrepõe a aspiração de igualdade que, segundo indica, pode acarretar em um ato de injustiça. Nessa perspectiva, o dilema entre "Liberdade X Igualdade" está montado, na medida em que a pretensão de igualdade pode terminar por exigir uma espécie de nivelamento por baixo dos talentos das pessoas, na impossibilidade de todas se encontrarem no mesmo patamar social e econômico. (NOZICK, 1974, p. 229)

10 Enquanto posições conservadoras, entendemos aquelas que endossam a justeza de haver desigualdades na sociedade, na compreensão do laissez faire do Livre Mercado. Para tais posições, se os indivíduos comercializam suas capacidades e seus bens no Livre Mercado, tem todo direito de ficarem com tudo que ganharem, consistindo em um equívoco a taxação governamental da renda obtida por esses meios tendo em vista o "benefício alheio", ou comunitário, pela promoção de políticas estatais. O Igualitarismo, por sua vez, entende que as desigualdades muitas vezes refletem a injustiça que se estabelece desde o início da vida em sociedade, oriundas, por exemplo, de fatos como nascimento em famílias afluentes ou empobrecidas, oportunidades de ensino e qualificação, entre outros. De maneira que, ao pensarmos em termos de justiça e desigualdade, retoma-se a célebre pergunta hipotética formulada por Rawls: supondo que não saibamos como será nosso futuro na sociedade, sem saber se seremos ricos ou pobres, fortes ou fracos, saudáveis ou doentes, com quais princípios de justiça concordaríamos ao não saber qual futuro teríamos? Cf. ANDERSON, 1999, p. 312.

11 Cf. ANDERSON, 1999, p. 312 
liberdade, dissolvendo assim a atribuição de um dilema que,supostamente,corrobora uma incongruência entre ambas e que os igualitaristas de recursos não conseguiram equalizar satisfatoriamente.

Mesmo os demais teóricos distributivistas, aqueles que não defendem propriamente uma distribuição de recursos, mas o que poderíamos chamar de uma distribuição de Bem-estar, segundo Anderson, partem dessa noção falha de igualdade e geram problemas difíceis de serem contornados. Em geral, isto ocorre porque tratam de prazeres e satisfações que são desfrutados de forma privada, que dificilmente encontram constância necessária para que sejam assumidos por todos coletivamente. Haja vista que o Bem-estar termina em muitos casos por compreender uma esfera intimista dos sujeitos e de extrema relativização e variação, o que implodiria a teses de suas teorias no sentido político. O substrato conceitual do igualitarismo como distribuição, ou melhor, redistribuição, é a compressão da igualdade como uma espécie de compensação por má sorte não merecida.

Nesse sentido, negligenciariam os objetivos propriamente políticos do Igualitarismo. Aliás, a pretensão nesse caso parece ser um tipo de realização de justiça cósmica, tendo em vista eliminar da vida humana o impacto e os eventuais prejuízos oriundos da sorte bruta. Segundo Dworkin, a condição natural e anterior à vida social, ou seja, não proveniente de uma escolha deliberada. O que queremos apontar é que a pauta central do Igualitarismo deveria, antes, se encontrar na questão da opressão socialmente imposta. Sendo assim, é necessário forjar uma comunidade em que os cidadãos estejam em condições de igualdade entre si e não estritamente preocupados na garantia e no recebimento de uma recompensa moral.

Quando se busca aplicar o que chamamos de justiça cósmica, feita por mãos humanas, queremos dizer que o objetivo prático de uma espécie de igualitarismo da sorte consiste em uma forma de compensação aos indivíduos por infortúnios e flagelos advindos por natureza. As vertentes mais recentes do igualitarismo adotam um critério leximin da igualdade, isto é; admitindo até que ocorram desigualdades inevitáveis, porém, considerando sempre os de inferior situação tendo em vista beneficiá-los ou, pelo menos, não prejudicá-los. Essa posição teórica entende que é um ato de justiça retirar dos mais abastados parte de suas vantagens, notavelmente não merecidas por eles, 
uma vez que adquiriram essas vantagens em razão da sorte bruta ${ }^{12}$. Contudo, essa posição também acarreta objeções, mais uma vez acusando o igualitarismo de prescindir da responsabilidade individual, quando, em sua ação de justiça cósmica, intenta garantir os mesmos resultados dispensando as pessoas das escolhas que fizeram. Essa crítica empurrou o igualitarismo para uma tese de igualdade de oportunidades, que também sugere ser muito coerente. O foco deixa de se concentrar nos resultados obtidos, passando a se concentrar nas oportunidades vigentes e acessíveis a todos para alcançar os resultados pretendidos.

Ainda que permaneça dentro de uma perspectiva de compensação, todavia, já não é mais no atinente aos resultados e sim nas condições de disputa em sociedade. No entanto, a tese da igualdade de oportunidade teria o ônus em não se comprometer, de forma alguma, com as desigualdades oriundas das escolhas voluntárias, admitindo, por conseguinte, a justeza da desigualdade dos resultados ${ }^{13}$. Em geral, a consequência mais pragmática é a constituição deuma sociedade híbrida em seu modus operandi, quer dizer, operando dentro das regras capitalistas e ao mesmo tempo endossando às práticas do Estado de Bem-Estar Social (Welfare State). Nesse sentido, os igualitaristas da sorte, no que se refere aos resultados provenientes das escolhas voluntárias das pessoas, são de um individualismo rigoroso. Quanto ao Estado de Bem-Estar, esse consistiria muito mais em uma espécie de exorbitante companhia de seguros e assistência social, mediante pagamento de impostos como um tipo de apólice de seguro ${ }^{14}$.

Naquilo que poderíamos conceber como uma tese de igualitarismo da sorte puro; se os indivíduos forem imprudentes não é uma demanda de justiça que a sociedade os socorra. Entretanto, nem todos os igualitaristas compactuariam com essa ideia, mas visariam enquanto alternativa uma espécie de seguro obrigatório. Em razão de alguma concisão e coerência entre os igualitaristas, poderíamos situá-los em dois grupos; os igualitaristas de recursos e os igualitaristas de bem-estar. A questão fundamental quanto a essa distinção para Anderson é: “os igualitaristas devem se importar com que as pessoas tenham oportunidades iguais de bem-estar ou apenas que sua fatia

12 "a justiça distributiva estipula que os sortudos devem transferir aos azarados parte ou todos os seus ganhos devidos à sorte”. (ANDERSON, 1999, p. 290)

13 É o que denominará enquanto uma distinção entre "sorte opcional” e "sorte bruta”.Cf. DWORKIN, 1981, p. 293

14 Cf. DWORKIN, 2005, p. 180 
de recurso seja igual?"15. Por um lado, aqueles que se concentram na vertente da distribuição de recursos defendem que as pessoas devem ter direito a recursos iguais, no entanto, devem ser também responsabilizadas pelos gostos que desenvolvem, de modo a equalizar tudo e assim viverem de maneira satisfatória. Por outro, os que se encontram na perspectiva do bem-estar apresentam três objeções aos da distribuição de recursos. Primeiro que, em geral, o critério que as pessoas teriam para avaliar seus recursos seria o bem-estar que tais recursos trariam. Segundo, que os igualitaristas de recursos responsabilizam equivocadamente as pessoas pelos gostos que tem. Por fim, ser difícil argumentar contra o fato de que pessoas com deficiência têm direito a mais recursos.

Anderson denuncia que ambas as correntes do igualitarismo da sorte centram seu interesse num tipo de demanda subjetiva, demanda que para eles termina por ocupar um papel central na medida de igualdade ${ }^{16}$. Isto porque, mesmo para os defensores da distribuição de recursos, esses recursos tem seu valor medido pelos preços de mercado dentro de um leilão hipotético. O que conferiria os preços adequados aos recursos? Evidentemente, a relação de oferta e demanda como também as preferências subjetivas por esses recursos. A crítica da filósofa é incisiva, na medida em que considera que o Igualitarismo,especificamente nas duas formas principais como se apresenta, estaria pautado por uma concepção falha de justiça. Essa concepção equivocada tem como produto inúmeras incoerências que encerram situações morais difíceis e notavelmente injustas, como as que podem ser encontradas nos diversos exemplos apresentados por Anderson que, sumariamente, destacamos a seguir: abandono de vítimas negligentes, discriminação entre deficientes, discriminação geográfica entre cidadãos, discriminação ocupacional, vulnerabilidade dos cuidadores dependentes, problemas da exploração e de falta de uma rede de proteção,além do abandono dos prudentes ${ }^{17}$.

Se retomarmos os argumentos de Dworkin contra Rawls, em que infere o direito à igualdade de tratamento como devido aos seres humanos enquanto pessoas morais, na circunstância em que tenhamos uma sociedade que permita que os seus cidadãos sucumbam às piores formas de indignidade, decorrente, muitas vezes, de escolhas

15 Cf. ANDERSON, 1999, p. 294

16 Cf. ANDERSON, 1999, p. 295

17 Cf. ANDERSON, 1999, p. 302 
totalmente razoáveis, certamente essa sociedade não poderia estar baseada em princípios igualitaristas, pois não os trata com respeito. Ademais, será que mesmo os imprudentes merecem destinos nefastos? Certamente não. E mesmo que os igualitaristas estejam abertos a admitir correções em seu sistema rígido, essas correções, quando feitas, tendem a um tipo de paternalismo.

Ora, se devemos abrir mão do Igualitarismo tal qual é apresentado pela concepção do igualitarismo da sorte, pois, como indicam os argumentos explicitados, são pautados por princípios equivocados de justiça, como também não se mostram imunes às críticas daqueles que atribuem um dilema para indeferir uma relação inerente entre liberdade e igualdade. É necessário, também, apresentar uma alternativa para essa teoria. Na esteira daquilo que nos propõe Elizabeth Anderson, nessa última parte exporemos os argumentos que nos inclinariam a uma possível adoção ao Igualitarismo Democrático. Retomemos aqui o argumento de que o igualitarismo de recursos ou bem estar endossa uma sociedade híbrida, institucionalmente, pelo menos. Disso decorre que,quanto aos bens fora do controle dos cidadãos, a sociedade operaria pela lógica do Estado de Bem-Estar social já que, no atinente aos bens atribuíveis a partir das escolhas individuais, aderisse ao Livre Mercado para realizar essa distribuição. Poderíamos assumir, então, que o Igualitarismo em sua acepção distributiva, propõe uma forma de conciliação entre o que há de melhor no capitalismo e no socialismo. Contudo, quando tomamos as implicações práticas oriundas dessas teses às consequências parecem difíceisde serem admitidas no seio de uma concepção igualitarista.

Isto sugere outro procedimento de articulação intelectual, dentro da perspectiva da chamada teoria crítica normativa. A rigor, tomando os vários movimentos igualitários historicamente constituídos, o que é possível auferir como aquilo que o Igualitarismo deveria sustentar? É esse o procedimento que será realizado por Anderson. Desses movimentosa filósofa aufere a ideia de reconhecimento dos indivíduos como iguais em toda a sua diversidade, a partir de uma concepção cosmopolita, propiciando arranjos institucionais que permitam que essa diversidade de talentos seja reconhecida como benéfica para toda sociedade. Notadamente, ocorre que não é isso que defendem os igualitaristas de recursos ou bem-estar. Como mostram as consequências inferidas de seus argumentos, estão mais próximos de uma visão hierarquizada de sociedade, munida de forte teor moral, fazendo acepção de pessoas entre os responsáveis e os imprudentes. Isto no que se refere à sorte opcional, pois, quando versam 
sobre a sorte bruta realizam uma verdadeira distinção entre os inferiores e os superiores por natureza. Aos que consideram imprudentes e irresponsáveis não oferecem nenhum auxílio, quanto aos que consideram inferiores por natureza, o que tem a oferecer é uma ajuda humilhante com o rótulo público de incapazes. Nessa concepção Igualitarista o Estado termina por ser um inquisidor e juiz moral dos cidadãos e não os trata com igual respeito e dignidade. Embora a dignidade dos indivíduos como pessoas morais tenha sido o estandarte de Dworkin, ao contrapor-seao modelo procedimental de Rawls, pelo viés jusnaturalista. É nesse ponto que reside à crítica de Anderson ao que ela denomina como igualitaristas da sorte e o caráter conversador que suas teses implicariam.

Se for uma sociedade hibrida,aquela que termina sendo sugerida peloigualitarismo da sorte, poderíamos assumir essa teoria então como uma "teoria de linha de largada". O ponto fulcral da sua tese consistiria apenas em estabelecer condições iniciais iguais, sem nenhuma responsabilidade sobre possíveis situações de sofrimento e sujeição de pessoas, claro, se essas pessoas fizeram isso em acordos voluntários em Livre Mercado. Certamente que Dworkin nega que sua posição seja algo como uma "teoria de linha de largada", mas isto porque defende uma espécie de compensação por talentos desiguais durante toda a vida ${ }^{18}$. Nesse sentido, é extremamente lacunar em não apresentar uma resposta a uma demanda premente do igualitarismo: fornecer princípios que oriente anseios coletivos, ou seja, que ultrapassem uma perspectiva meramente individualista, apresentando o que os cidadãos podem legitimamente aspirar coletivamente ${ }^{19}$.

Para pensar a respeito do que se pode aspirar coletivamente, faz-se necessário retomar as aspirações, em geral, dos movimentos políticos igualitaristas historicamente. Retomar a sua agenda e pautas em comum para encontrar, supõe-se, uma síntese e uma ponte possível entre eles. Nessa observação, notamos que o ponto fora não

18 Quando trata do leilão hipotético e dos seguros pessoais, além das consequências provenientes da regulação dos preços e valores pelo mercado, Dworkin gera mais problemas que soluções satisfatórias. Cada indivíduo decidir livremente se vale a pena comprar algo para o seu consumo privado não encontra dificuldades em nos convencer, contudo, não é persuasivo que o Estado ou o Livre Mercado decida pelos indivíduos sob o argumento de obrigá-los a socializar os custos de proporcionar esse bem a todos. Ou seja, não apresenta um argumento convincente sobre o que os cidadãos são obrigados a fornecer uns aos outros em uma base coletiva. Cf. DWORKIN, 1981, pp. 309-311.

19 Cf. ANDERSON, 1999, p. 312. 
tanto à distribuição de bens, mas, sobretudo, às relações entre pessoas superiores e inferiores, dominantes e dominados. Quando se observa sob um prisma histórico, vê-se que sujeitos tomados como superiores tiveram o direito e legalidade de infringir violência aos considerados inferiores, podendo assim excluí-los e segregá-los da vida social. Nesse sentido, Anderson se alinha a uma postura intelectual mais próxima aos procedimentos descritivistas da teoria crítica para constituir sua tese. No entanto, é importante notar que o chamadoigualitarismo democrático também almeja um procedimento prescritivo que encontrará auxílio argumentativo na teoria política normativa de Amartya Sen.

Retomando as teses de Sen acerca da Capability Approach, se constitui aquilo que Anderson compreende como o igualitarismo democrático, enquanto uma alternativa possível ao igualitarismo da sorte. No intento de evidenciar uma conciliação inerente, porém, tantas vezes negligenciada, entre igualdade e liberdade como facetas complementares e constituintes da nossa compreensão de justiça no cerne do Igualitarismo. A rigor, o que Sen compreende por meio do neologismo Capability Approachconsiste nos conjuntos de funcionamentos que uma pessoa consegue dispor. De acordo com essa abordagem, o bem-estar e o desenvolvimento devem ser pensados em termos de capacidades para realização de determinadas funções, quer dizer, sobre as possibilidades efetivas para realização de atividades que os indivíduos querem exercer tomando em consideração as reais condições sociais para ser quem querem ser ${ }^{20}$. Por funcionamentos (achieved functionings) se entende o conjunto formado entre ser e fazer que constituem o bem-estar de uma pessoa. Tais funcionamentos que integram ascapabilities como pensa Sen, dependem, antes, dos recursos pessoais, materiais e sociais que alguém dispõe ${ }^{21}$. Por sua vez, as capabilities não são mensuradas por funcionamentos efetivos, mas pela liberdade que um indivíduo encontra em adquirir funcionamentos valorizados ${ }^{22}$. Entretanto, politicamente, a tese das capabilities é lacunar em não indicar quais são as capacidades que a sociedade tem obrigação de equalizar. Inclusive, quanto aos limites de capacidades que os cidadãos são obrigados

20 Cf. SEN, 2008, p. 253

21 Optamos em manter o termo capabilities em inglês, embora pudéssemos traduzi-lo por capacidades. No entanto, essa tradução não dá conta da abrangência do termo original, de modo que para esse trabalho em muitos momentos preferimos o uso do termo como encontramos em Amartya Sen.

22 Cf. SEN, 2008 , pp. 253-256. 
a proporcionar uns aos outros. Na tentativa de uma resposta ou complementação podemos encontrar os argumentos que constituem o igualitarismo democrático.

Na teoria de Sen, os funcionamentos não incluem apenas aqueles mais básicos e primários, tais como, ser saudável, nutrido, alfabetizado, mas também funcionamento que podemos dizer mais complexos, como fazer parte de uma comunidade e ser respeitado, por exemplo. O que a Capability Approach indica é que uma teoria da igualdade precisa levar em consideração o indivíduo, priorizando-o, como também o seu entorno social que fomenta a possibilidade ao indivíduo de usufruir sua liberdade e por meio dela viver a vida que almeja, favorecendo a execução de seus planos. Somente desfrutando de sua liberdade os indivíduos podem desempenhar a vida que para si mesmo tem valor e significado.Note-se que, para o exercício de liberdade na sociedade, os cidadãos precisam dispor de quaisquer capabilities imprescindíveis para atuarem como iguais e não serem enredados em relações de opressão. Em um Estado democrático os cidadãos precisam dispor dessas capacidades necessárias para atuarem como iguais, portanto, essas capacidades se constituem como direitos. A liberdade, no entanto, não está circunscrita ao âmbito coletivo apenas, para o igualitarismo a liberdade deveria também ser garantida na esfera privada, isto é, precisa ser garantido que os indivíduos não sejam submetidos a relações privadas de dominação.

A tese do igualitarismo democrático na medida em que se sustenta sobre esses argumentos, exige a satisfação de amplas capacidades para que os indivíduos funcionem como humanos, como participantes de um sistema de produção cooperativa e como cidadão de um Estado democrático. Essa teoria tem como substrato conceitual a concepção de sociedade como um sistema cooperativo que proporciona uma rede de apoio, de maneira que mesmo aqueles que seriam considerados imprudentes, dentro da perspectiva do igualitarismo da sorte, não seriam inevitavelmente colocados de lado e forçados a sucumbir a uma situação de indignidade humana, pois dentro do seio da teoria defendida por Anderson o igualitarismo tem como principal objetivo não permitir que os indivíduos, seja na esfera pública ou privada, sejam passíveis de opressão e dominação.

Isso supõe que, dentro de um sistema produtivo, ninguém receba benefícios inadequados. Em que consistiria esses benefícios inadequados? Tomamos o fato de alguém ter um trabalho, notavelmente um benefício diante do malefício do desemprego con- 
siderando um sistema de cooperação produtiva, esse benefício não pode acarretar o ônus de perda de condições sociais de sua liberdade, por exemplo. Nenhum trabalho na sociedade pode impor aos trabalhadores uma condição de servidão ou escravidão, isso significa também que não poderá pagar-lhe valor tão irrisório que essa pessoa ainda careça de recursos básicos, sugerindo, de antemão, um salário mínimo quando de trabalho em tempo integral. Portanto, o igualitarismo democrático precisa assumir o espaço do Livre Mercado e da economia dentro de suas implicações práticas, desse modo, ao contrário do igualitarismo de recursos, não entrega os indivíduos à regência desses meios alegando uma espécie de servidão voluntária ou má sorte opcional ${ }^{23}$.

Rawls é contrário a qualquer desigualdade de renda que não melhore a renda dos menos favorecidos na sociedade por meio do que denomina como "princípio da diferença" ${ }^{24}$. A tese rawlsiana, em função da igualdade, parece muito exigente quando consideramos as faixas intermediárias na sociedade que terminam tendo uma oneração maior na carga tributária e a renda das classes populares permanece mantida em valores irrisórios. A lacuna existente entre ricos e pobres continua sendo uma das questões centrais quando tratamos da justiça hoje, lacuna crescente presente em países como o Brasil, por exemplo. A maneira de lidar com essa questão pelo simples laissez faire, além de individualista dentro de um contexto comunitário que por princípio é a vida em sociedade, não responde as demandas cada vez maiores e exigentes de legítimos movimentos igualitaristas, para além da pauta identitária, mas que também permeada por ela, descontentes com a exorbitante discrepância de renda ${ }^{25}$.

23 O argumento é que aqueles que dispõem na sociedade de trabalhos de alta produtividade e socialmente reconhecidos, devem muito da sua produtividade ao fato de disporem de maior tempo. E por que esses indivíduos dispõem de mais tempo? Exatamente porque não precisam gastar seu tempo em tarefas de baixa qualificação e, se não precisam ocupar seu tempo com tais demandas isso é explicado pelo fato de alguém fazer isso por eles. Ao exercerem tarefas rotineiras e de baixa qualificação esses indivíduos liberam outros para que realizem atividades mais produtivas socialmente. Percebe-se que, um grande executivo não poderia fechar importantes contratos caso tivesse de atender todos os telefonemas que recebe no escritório e talvez não conseguisse articular todas as exigências desses contratos sem o auxílio de outras pessoas, na hierarquia empresarial, seus subordinados. O igualitarismo democrático apela para uma ideia de comunidade onde todos se beneficiam da diversidade de talentos e atividades na sociedade. E mais: contraria a tese de que os trabalhos que desempenham atividades melhor socialmente reconhecidas, com robustas remunerações e que residem no todo da pirâmide social dão maior contribuição ao produto final coletivo.

24 Cf. RAWLS, 1975, p.75

25 Para uma abordagem acadêmica sobre a pobreza e desigualdade levando em conta a discussão acerca da diversidade sociocultural sugerimos o trabalho de Michael Jindra intitulado O Dilema 
Há, por certo, uma distinção fundamental quando tratamos da má sorte bruta; advinda, dentro da tese do igualitarismo da sorte, por uma determinação da natureza. Para Anderson, os chamados “dons naturais inferiores” não estabelecem uma relação necessária com as desigualdades de renda observadas nas economias capitalistas. Aliás, é fato notório que as maiores fortunas não são oriundas do trabalho, mas alcançadas por aqueles que possuem os meios de produção. Na sociedade a desigualdade se dá por uma opção muito obscuramente fundamentada de atribuir maior capital a algumas atividades e não outras. De antemão, o capital já está disposto na sociedade de forma desigual para cada trabalhador, pois, a noção de valor de produção se vincula muito mais a papéis profissionais que aos indivíduos em si. Ao considerar a sociedade, como dissemos, enquanto um sistema de cooperação, a igualdade democrática atua de maneira menos degradante quando das intervenções estatais, não parte do princípio que o impedimento do indivíduo para conseguir um trabalho melhor seja suas condições naturais inferiores, dons naturais escassos comparados a outras pessoas. O que propõe é uma melhor e maior apreciação do trabalho desenvolvido por pessoas de remuneração mais baixa, portanto, não apela para uma justiça cósmica como no caso do igualitarismo da sorte.

De todo modo, o que o igualitarismo democrático propõe como alternativa é que os indivíduos disponham de um conjunto relevante de liberdades, suficientes para que funcionem como iguais na sociedade, nesse sentido, a desigualdade de renda não ocuparia um lugar tão relevante, o que não significa que não tenha importância. Notemos que o argumento é evitar uma espécie de mercantilização do status em sociedade, isto é, situação onde aqueles com maior renda são melhor coletivamente valorizados. Perceba-se que, se Igualitarismo deve considerar os cidadãos igualmente em respeito

da Igualdade e Diversidade, onde assinala: "Para entender as tensões entre diversidade e igualdade, precisamos de uma compreensão adequada da diversidade do estilo de vida, o que também significa reconsiderar alguns dos tabus sobre a incorporação da cultura. Esta será uma empresa complicada, mas vale a pena se isso nos revelar melhor o que contribui para a pobreza e a desigualdade, mantendo-se sensível à diversidade. Apesar de algum trabalho etnográfico sobre os pobres, ainda parece haver uma grande distância entre a antropologia da pobreza e a desigualdade e a realidade das vidas dos pobres e das organizações que trabalham no alívio da pobreza. As narrativas acadêmicas padrão não abordam adequadamente os aspectos estruturais e culturais da vida dos pobres ou as tensões relacionadas entre os valores centrais da diversidade e da igualdade. Por suas abordagens estruturais unilaterais, os estudiosos de estratificação ficam vulneráveis à críticas pouco rigorosas de intelectuais que escrevem para um público mais amplo". (JINDRA, 2014, p. 325) [Tradução própria]. 
e dignidade, não pode admitir uma desigualdade no sentido de hierarquizar a sociedade. No caso, essa hierarquia não se refere à disparidade econômica, mas no que concerne ao status social que as pessoas possuem. Quanto à disparidade econômica, sugere diminuir o abismo que encontramos entre os trabalhadores de menor e maior remuneração por meio de uma forte noção de reciprocidade na sociedade, motivados por uma concepção de cooperação $\operatorname{social}^{26}$. O valor e a dignidade das pessoas não são ditados pelo Livre Mercado. Além disso, a renda deve ser incluída no rol das capacidades necessárias, politicamente, para não serem sujeitadas e oprimidas ${ }^{27}$.

Os igualitaristas, independente de suas vertentes, precisam admitir e argumentar de maneira a não negligenciar a responsabilidade pessoal. Quanto mais eficientes são em equacionar de forma satisfatória a relação entre igualdade e liberdade, mais competentes se mostram na dissolução do dilema. Se a contradição entre os dois princípios é falsa no seio do Igualitarismo, a questão seguinte e premente consiste certamente em definir o que é a igualdade. Desde Rawls e a retoma do contrato social para justificação de uma sociedade democrática justa, somos incitados a perguntar-se a respeito da razão de existência do Estado e quais os parâmetros para gerência da sociedade ${ }^{28}$.

26 Essa tese parece flertar com algum tipo de comunitarismo,visando, como o próprio nome diz, uma preocupação com a comunidade e também com a grande lacuna entre ricos e pobres. Contudo, temos razões diferentes operando. Não se trata apenas da preocupação com a injustiça para com os de classes mais baixas, que sofrem com suas desvantagens e são sujeitos à opressão como defende o igualitarismo democrático. Para o comunitarismo, caso tenhamos uma lacuna grande demais entre ricos e pobres será muito difícil sustentar uma noção de comunidade, a noção de que a vida social é um projeto comum, que envolve uma cidadania compartilhada, no qual os cidadãos se sentem comprometidos uns com os outros porque estão comprometidos com um projeto comum. Para essa vertente o problema da desigualdade é visto a partir do ponto da coesão social, da solidariedade e da comunidade.

27 Anderson ainda tem lacunas não preenchidas nas soluções que o igualitarismo democrático precisa dar as questões que se referem às desigualdades de cunho econômico em sociedades regidas por uma dinâmica capitalista. No tocante a essas questões recomenda-se a leitura de sua obra mais recente intitulada "Liberty, Equality and Private Government (ANDERSON, 2015)".

28 Nesse sentido, nos auxilia a distinção destacada por Velasco: "Se a igualdade é um fim (télos) a ser alcançado, a estrutura do agir será teleológica, e a ação a ser realizada consistirá em achar os melhores meios para atingir esse fim. Em contraste, quando a igualdade está sendo entendida como um direito, ela não está sendo entendida como um fim a ser alcançado, mas como um valor que deve ser respeitado, portanto, como uma restrição a qualquer outro fim que possamos perseguir". (VELASCO, 2009, p.130) 
Por sua vez, o igualitarismo democrático proposto por Elizabeth Anderson não configura a justiça em termos distributivos, mas em termos relacionais. O que não significa que, mesmo dentro de uma concepção relacional de justiça, não devamos admitir que para sua satisfação existam também demandas distributivas, como no caso das capacidades que se entendem como direitos a serem supridos pelo Estado, mas esse não é o princípio norteador, básico e primeiro. A teoria crítica demanda sobre as teorias da justiça que sejam capazes de dar conta de injustiças sociais concretas, alegando que tais teorias mostram-se ineficazes nesse propósito. No entanto, Anderson, que parte de uma atitude descritivista mais próxima à teoria crítica - no sentido de retomar e considerar as exigências historicamente demandadas pelo Igualitarismo nas pautas dos movimentos sociais - elabora também um procedimento prescritivo comum aos pensadores das teorias da justiça. Defendendo sua tese numa espécie de teoria crítica normativa. Portanto, tem o mérito de realinhar a produção acadêmica com os movimentos políticos igualitários realmente existentes e dar uma resposta que, em vista das objeções endereçadas às demais formas de Igualitarismo, mostra-se mais competente em mantê-lo imune ao dilema "Igualdade X Liberdade", reiterando-o enquanto falso.

\section{REFERÊNCIAS BIBLIOGRÁFICAS}

ANDERSON, Elizabeth. What is the point of Equality?In: Ethics, Vol. 109. University of Chicago Press, Chicago, 1999.

ANDERSON, Elizabeth.Qual é o sentido da Igualdade? Trad.: Roberto Costa. Revisão técnica: Flávia Biroli. In: Revista Brasileira de Ciência Política, N.15. Brasília, 2014.

ANDERSON, Elizabeth. Liberty, Equality and Private Government. The Tanner Lectures in Human Values. Princeton University Press, 2015.

ARAÚJO, Marcelo. A fudamentação contratualista dos direitos humanos. Étic@, Florianópolis, $\mathrm{n}^{\circ}$ 03, Volume 08, 2009.

DALL'AGNOL, Darlei. O Igualitarismo Liberal de Dworkin. In: KRITERION, Belo Horizonte, $\mathrm{n}^{\circ} 111,2005$. 
DWORKIN, Ronald.What is Equality? Part 2: Equality of Resources. Philosophy and Public Affairs. Vol. 10, nº 04, p. 283-345, 1981.

DWORKIN, Ronald. Virtude Soberana. Teoria e prática da igualdade. São Paulo: Martins Fontes, 2005 .

DWORKIN, Ronald. The Original Position. In; DANIELS, N. Reading Rawl. Critical studies in Rawls' A theory of justice. Stanford: University Press, 1975.

JINDRA, Michael. The Dilemma of Equality and Diversity. In: Current Antropology, Vol. 55, N.3, p.316-334. Chicago: The University of Chicago Press, 2014.

NOZICK, Robert.Anarquia, Estado e Utopia. Rio de Janeiro: Zahar, 1991.

PETRONI, Lucas. A Moralidade da Igualdade. Tese. Ciência Política. Universidade de São Paulo, São Paulo, 2017.

POPPER, Karl.The Open Society and Its Enemies. Princeton, Princeton University Press, 1966.

RAWLS, John. A Theory of Justice. Cambridge: Harvard University Press, 1975.

RAWLS, John.Uma Teoria da Justiça. São Paulo: Martins Fontes, 2002.

SEN, Amartya. Igualdade de quê? Em Desigualdade Reexaminada. Rio de Janeiro: Record, 2008.

SEN, Amartya. The Idea of Justice. Cambridge: The Belknap Press, 2009.

VAN PARIJS, Philippe.Real Freedom for All: What (if anything) can justify capitalism?Oxford: Claredon Press, 1995.

VELASCO, Marina. O que é justiça?Rio de Janeiro: Vieira\&Lent, 2009. 